\title{
La etapa formativa de Picasso en Galicia
}

\section{The Formative Stage of Picasso in Galicia}

\author{
Inmaculada ZuRRóN LóPEZ
}

Universidad Complutense de Madrid Departamento de Arte III

inmaculadazurron@gmail.com

[recibido 12/02/2015, aceptado 15/07/2015]

\section{RESUMEN}

Este artículo reconoce la importancia del periodo de escasos cinco años que Picasso pasó en A Coruña, el lugar donde inició sus estudios artísticos. A través de la narración de los acontecimientos vividos por el artista en Galicia, el objetivo de este texto es confrontar su obra de formación en tierras gallegas con su obra posterior donde se puede apreciar una estrecha relación tanto en los temas como las composiciones e incluso los colores.

Palabras Clave: Arte, Galicia, A Coruña, Picasso, Raimundo Pérez Costales.

\section{RESUMO}

Este artigo recoñece a importancia do período de escasos cinco anos que Picasso pasou na Coruña, o lugar onde iniciou os seus estudos artísticos. A través da narración dos acontecementos vividos polo artista en Galicia, o obxectivo deste texto é confrontar a súa obra de formación en terras galegas coa súa obra posterior onde se pode apreciar unha estreita relación tanto nos temas como as composicións e mesmo as cores.

Palabras Chave: Arte, Galicia, A Coruña, Picasso, Raimundo Pérez Costales.

\section{ABSTRACT}

This article recognizes the importance of Picasso's brief five year stay in A Coruna, being the place where he began his artistic studies. Through the narration of the events experienced by the artist in Galicia, the objective of this text is to compare his work at that time with his later paintings. In both stages one can appreciate similarities in composition and the use of colour.

KEYwORDs: Art, Galicia, A Coruña, Picasso, Raimundo Pérez Costales.

Zurrón López, I. (2015): “La etapa formativa de Picasso en Galicia”, Madrygal. Revista de Estudios Gallegos (Madr.), 18: $157-161$ 
El gran desconocimiento de la etapa formativa de Picasso en Galicia es sorprendente teniendo en cuenta la importancia internacional del pintor malagueño. Puede ser porque para el propio pintor fue una época repudiada a lo largo de toda su vida, ya que se trata de una etapa de aprendizaje académico; una etapa a la que el propio artista siempre se refiere como el período que durante toda su vida se esforzó en desaprender. También porque posee un inmenso y amargo tinte personal: la muerte de su hermana pequeña Conchita, hecho que culminó la inadaptación de la familia Ruiz Picasso en estas tierras. Un sentimiento de extranjería, aislamiento, que describe muy bien O’Brian (1977: 40) en su biografía sobre el artista, en su opinión tanto por los problemas de comunicación (hablaban una lengua distinta), como por las inclemencias del tiempo: persistente lluvia, el frío y la niebla cargada de humo. En definitiva, un ambiente tan contrario al de la Málaga que bien conocían. Otro de los motivos que se deducen es que debido a su manifiesta, valiosísima y profusa obra posterior, se haya hecho sombra a la producción de este periodo tan corto e inicial de su arte. En realidad todos aquellos que se han dedicado a estudiar a este gran genio tratan con demasiada brevedad esta etapa.

El motivo de que una familia malagueña de clase media cruzara prácticamente toda la Península Ibérica de sur a norte no fue otro que el económico. José Ruíz, padre del prolífico artista, era un modesto profesor de la Escuela de Bellas Artes y, a su vez, conservador del Museo Municipal de Málaga. Su principal fuente de ingresos procedía de esta última institución y, tras su cierre, se encontró en una situación económica muy precaria. La solución fue aceptar la plaza de profesor de dibujo en la Escuela de Bellas Artes de A Guarda (A Coruña). Toda la familia se trasladó allí en septiembre de 1891. Emprendieron un viaje largo e incómodo en barco; un medio que les resultaba más económico, ya que uno de los hermanos del profesor era el jefe de los servicios sanitarios del puerto. Fue un viaje tan pesado que hizo que la familia decidiera desembarcar en Vigo e ir por tierra, en tren y diligencia, hasta A Coruña.

Una vez instalados allí, Picasso siguió asistiendo a la escuela secundaria común, pero por poco tiempo, ya que desde su estancia escolar en Málaga dio síntomas de desinterés por las materias obligatorias escolares. En 1892 Picasso consiguió convencer a su padre para que intercediera por él y comenzar así su formación en la Escuela de Bellas Artes de A Guarda, donde enseñaba su padre. Lo más significativo de su entrada en esta escuela provincial de Bellas Artes es que Picasso no cumplía la edad mínima para asistir a dichas clases; por tanto, su padre tuvo que mentir sobre su edad $^{1}$. Estuvo en esta escuela hasta 1895, comenzando por las asignaturas de dibujo ornamental y luego de dibujo de figura humana, para frecuentar finalmente las clases dedicadas a la copia de objetos de yeso en general, el dibujo de la figura humana realizada en yeso y la copia y pintura según modelos naturales. De esa manera, se sometió a una severa educación académica de acuerdo con las normas de la Real Academia de Bellas Artes de Madrid, que seguía un método de aprendizaje basado en la máxima "el alumno tiene que aprender guiado por el maestro", como dice Cenini en El libro del arte (1988: 135 y ss.). El aprendizaje se iniciaba con una instrucción del dibujo desde lo simple a lo complejo a través de modelos de otros maestros, con la intención de adiestrar la mano del alumno, tal y como mencionan Leonardo da Vinci (2004) y Giorgo Vasari (1998) en sus tratados.

En su estancia en la Escuela de Bellas Artes de A Guarda, según cuenta Padín (1991: 47 y ss.), uno de los profesores que más influyó al joven artista fue Isidro Brocos Gómez, profesor de Adorno y Figura y titular de Modelado

\footnotetext{
${ }^{1}$ Padín (1991: 31) pone en cuestión si el error de la edad es debido a un despiste o de manera consciente, ya que la edad marcada por ley para el ingreso en la academia era de 12 años.
} 
y Vaciado de Adorno, del cual copió y luego creó su propio álbum denominado "Álbum de La Coruña". Brocos transmite a Picasso su gran admiración por Goya y El Greco. Debido a sus estancias en París y Roma poseía una mirada más moderna y progresista respecto al arte y es esta visión artística la que influirá en el aprendiz de pintor. Aún así, la formación que recibe el joven Picasso no deja de ser la aceptada por la Academia, aquella que sigue los tratados más antiguos y donde el dibujo es la disciplina constante en el desarrollo y consolidación de un artista. Esto se materializó en su obra realizada en A Guarda, dominada por los ejercicios de dibujo academicista y donde se percibe su proceso de evolución y maduración. Predominan los bocetos dibujados a partir de lo que percibía en su entorno más cercano, realizados con más o menos detalle, pero en todas las ocasiones intentando captar la realidad sin disfrazarla, una realidad bastante más pura que la que con posterioridad nos encontraremos en sus obras del Período Azul y Rosa.

En su obra coruñesa se advierten trazados de enfoques y técnicas diferentes; no hay que olvidar que se trata de una obra de formación. En sus primeros bocetos en Galicia posee una esencia más bien infantil, predominando las ilustraciones satíricas alusivas al mal tiempo coruñés. También son destacables los esbozos realizados en los márgenes de los libros de texto donde representaba romanos, salvajes, hombres con lanzas y espadachines en actitud de lucha. A esto podemos añadir dibujos de escenas de toros y palomas. Este último tema era el sello de identidad de la obra de su padre. Dibuja todo lo que ve en su entorno más próximo; por ello, los modelos utilizados no son profesionales, sino las personas más cercanas al artista, como son sus padres o sus hermanas Lola y Conchita.

Los álbumes de dibujo de esta época reflejan la plena concienciación del genio; es decir, sus obras tienen el carácter de ser documentadas. Con ello me refiero a que el propio Picasso anota la fecha de ejecución de cada una de las obras que se mantuvieron bien conservadas a lo largo del tiempo. En el primer álbum del pequeño artista, realiza algunas vistas de los alrededores de A Coruña y diversos apuntes tomados de la realidad. Aquí también se percibe este carácter documental, ya que solo dibujaba en las páginas impares y en las pares escribía el título de la obra o de dónde eran los bocetos tomados. Seguidamente se empiezan a alternar los trazos de lápiz con los de pluma, perdiendo el riguroso orden inicial, situando los esbozos en cualquier hoja y en diversas posiciones.

El segundo álbum, de idéntico formato al primero, comprende las obras ejecutadas entre el 12 de octubre de 1894 y principios de 1895. Aquí aparecen ya algunos rasgos distintivos del futuro Picasso, como es el fechar sus obras. También se caracteriza por no aislar o preservar los dibujos que estén mejor o bien acabados; en este sentido, no respeta sus propias obras, sino que en la misma hoja realiza esbozos de otra cosa. Del mismo modo, se caracterizan por su dinamismo: su obra avanza, se aprecia una progresión del relato, en los personajes, en la historia que nos relata. No se trata de apuntes de momentos estáticos, sino de un fluir constante (Palau i Fabre 1980: 4854). En el mismo álbum se encuentran estudios de manos y representaciones de su padre. Son retratos de una elevada penetración psicológica en una edad bastante temprana.

Fuera de la escuela, la obra del joven Picasso es mucho más libre. Entre los óleos que se conservan hay unos cuantos de pequeño tamaño con obras rápidas, en general paisajes coruñeses fechados entre 1894 y 1895. En sus restantes obras coruñesas pueden discriminarse escenas de la vida cotidiana de un muchacho, interiores y otras escenas donde se denota la influencia de los amigos de su padre,

\footnotetext{
${ }^{2}$ Este álbum se encuentra actualmente en el Museo Picasso de Barcelona.
} 
Ferrándiz y Muñoz Degrain; otras libretas de apuntes, dibujos de manos y lienzos.

Uno de los episodios que se cuentan en la biografía del artista realizada por Penrose (1981) y que muchos estudiosos de la materia han dado por cierto, es el hecho conocido de que don José permitía a Picasso acabar ciertas partes de sus obras, particularmente las patas de las aves muertas, que el pequeño tomaba de un modelo al natural. El profesor cada vez pintaba menos, había decaído su ánimo, a lo que también se le unía una creciente fatiga visual que no le permitía pintar con la misma agilidad. Se dice que un día determinado Picasso terminó por entero la obra de su padre; éste, asombrado, reaccionó donándole sus propios pinceles y colores, en clara señal de traspaso del legado a su hijo, $\mathrm{y}$, según se cuenta, nunca más volvió a pintar (Penrose 1981: 26-27). Este suceso, sin embargo, se sabe que realmente no tuvo lugar, ya que es cierto que el padre del artista disminuyó su producción en gran medida durante este periodo, pero siguió pintando.

Como documentación singular y sirviendo de precedente a su revista Arte Joven, conservamos el diseño, producción y edición íntegramente a mano, en formato revista, de la correspondencia con su familia malagueña durante su estancia en A Coruña. La revista casera no poseía un título fijo: en ocasiones se encabezaba bajo el nombre de "La Coruña", y otras veces "Asul y Blanco"3. Las noticias que contenía dicha revista solían ser de índole general, con referencias satíricas y con un tema claramente predominante: el mal tiempo típico de las tierras gallegas. Este boletín consistía en un folio doblado a la mitad, conformando una cuartilla de cuatro caras. En las diferentes revistas realizadas durante su estancia coruñesa, se puede percibir, al igual que en su obra plástica, tanto sus cambios de madurez mental como artística.

Un acontecimiento llamativo en la vida de un artista novel es la realización de su primera exposición en un local poco habitual para albergar cuadros: una tienda dedicada esencialmente a los paraguas (O’Brian 1977: 49). El éxito de la muestra no fue el deseado, lo cual se achacó a que los posibles compradores sabían que se trataba de obras realizadas por un niño de trece años. En la crítica a dicha exposición, publicada en el diario La Voz de Galicia del 21 de febrero de 1895, se alaba el que sea una obra de cierta calidad formal y cromática realizada por un artista tan joven: "la ejecución denota verdadera valentía, como si los pinceles en vez de ser manejados por débil mano, lo fuesen por la de un pintor ya avezado al trabajo"4.

Otro acontecimiento llamativo es que en el transcurso de su estancia gallega consigue a su primer mecenas, el doctor Raimundo Pérez Costales, quien había sido ministro de Fomento en la corta Primera República de Pi y Maragall en 1873. Era el médico de la familia y quien trataba de una "angina disférica" a la pequeña de la familia. Recuérdese la anécdota de que el doctor Pérez Costales le daba a Picasso las tapas de madera de las cajas de puros que él fumaba y éste se las devolvía pintadas a precio de un duro o de otra tapa; se trata de una leyenda que Picasso desmintió y que mencionó como una circunstancia puntual. Lo que sí es cierto es que el doctor, con un agudo sentido del arte, supo ver en el joven artista su calidad y fue quien le realizó sus primeros encargos, como el retrato a Modesto Castillo, hijo ilegítimo de Pérez Costales, disfrazado de moro. El doctor quería que Picasso lo retratase con una chilaba, pero como no tenía ninguna, el

\footnotetext{
${ }^{3}$ Guiño a la famosa revista titulada Blanco y Negro, el semanario más popular de la época dirigido a un público burgués. También se inspiró en un diario teatral, Teatro Crítico, al que su familia estaba suscrita y donde él quería colaborar. Al utilizar el término "asul" queda patente así que Picasso no pierde su acento andaluz en su estancia en A Coruña.

${ }^{4}$ Dicha crítica probablemente fuese responsabilidad de Alejandro Barreiro Noya (Padín 1991: 109).
} 
joven ideó una especie de túnica poniéndole un albornoz de felpa. Éste será un aspecto recurrente en los retratos de Picasso; con posterioridad se verá también, por ejemplo, en el retrato que en 1917 le hace a su esposa Olga Koklova con mantilla, en la que esta se sustituye por un simple tapete ${ }^{5}$.

Acabará la etapa gallega del pintor malagueño, una vez más, a consecuencia de una nueva oferta de empleo de su padre, un traslado a la Escuela de Bellas Artes de Barcelona, gracias a un intercambio de plaza que realizó con el pintor gallego Román Navarro en el verano de 1895 .
Podríamos resumir, entonces, la estancia de Picasso en Galicia como su etapa de iniciación artística, sobre todo en cuanto a lo académico se refiere, siendo a la vez precedente tanto en temas, composiciones y colores de obras que realizará con posterioridad tanto en Barcelona como en París. Si bien es cierto que ya con anterioridad, en Málaga, había tenido contacto con la pintura a través de la realización del que se conoce como su primer lienzo, "El Picador" (1889-1890), es en tierras gallegas donde recibe su formación en el aprendizaje del dibujo y de la pintura; y es allí donde se forjó un genio.

\section{REFERENCIAS BIBLIOGRÁFICAS}

Cennini, Ceninno (1988): El libro del arte. Akal: Madrid.

DA VincI, Leonardo (2004): Tratado de pintura. Akal: Madrid.

MaIler, Norman (1996): Portrait of Picasso as a Young Man. Canadá: Knopf.

O’ Brian, Patrick (1977): Picasso. Barcelona: Knopf.

Padín, Angel (1991): Los cinco años coruñeses de Pablo Ruiz Picasso (1891-1895). A Coruña: Deputación Provincial.

Palau i Fabre, Josep (1980): Picasso Vivent (1881-1907). Barcelona: Polígrafa.

Penrose, Roland (1981): Picasso su vida y su obra. Barcelona: Argos Vergara (trad. H. González Trejo).

RichARDSON, John (1995): Picasso, una biografia (1881-1906). Madrid: Alianza editorial (trad. A. Gómez Cerdillo, E. Gómez Parro y R. Jackson Martín).

VASARI, Giorgio (1998): Las vidas de los más excelentes arquitectos, pintores y escultores italianos desde Cimabue a nuestros tiempos. Madrid: Tecnos.

Walther, Ingo (2007): Pablo Picasso I (Obras 1890-1936). Köln: Taschen.

${ }^{5}$ En la actualidad este cuadro se encuentra en el Museo Picasso de Málaga. 